\title{
MLP Back Propagation Artificial Neural Network for Solar Resource Forecasting in Equatorial Areas
}

\author{
Marcello Anderson F. B. Lima ${ }^{1}$, Paulo C. M. Carvalho ${ }^{1}$, Arthur P. de S. Braga ${ }^{1}$, Luis M. Fernández Ramírez ${ }^{2}$, \\ Josileudo R. Leite ${ }^{3}$, \\ ${ }^{1}$ Department of Electrical Engineering \\ Federal University of Ceara - UFC \\ Campus Pici, Av. Mister Hull, s/n - Pici, Fortaleza, 60455-760, Ceará (Brazil) \\ Phone/Fax number:+558533669585, e-mail: marcello@ifce.edu.br, carvalho@dee.ufc.br, arthurp@dee.ufc.br \\ ${ }^{2}$ Department of Electrical Engineering \\ University of Cadiz - UCA \\ Escuela Politécnica Superior de Algeciras, Av. Ramón Puyol, s/n, Algeciras, 11202, Cádiz (Spain) \\ Phone/Fax number:+34956028166, e-mail: luis.fernandez@uca.es \\ ${ }^{3}$ Department of Industrial Mechatronics \\ Federal Institute of Education, Science and Technology - IFCE \\ Campus Limoeiro do Norte, Rua Estevão Remígio de Freitas, 1145 - Monsenhor Otávio, Limoeiro do Norte, 62930-000, \\ Ceará (Brazil) \\ Phone/Fax number:+558834476400, e-mail: josileudorodrigues@hotmail.com
}

\begin{abstract}
Renewable energy (RE) resources such as solar are increasingly being used worldwide. Solar resource shows high availability, but presents an intermittent characteristic, causing oscillations in the electricity production. Intermittence is one of the main barriers for the use of solar plants in a system that needs to balance demand and electricity production. Aiming to contribute to a larger use of the solar resource in the world energy matrix, we propose a solar irradiance prediction methodology, developed from data collected in Fortaleza-CE (latitude: $-03^{\circ} 43^{\prime}$, longitude: $-38^{\circ} 32^{\prime}$ ). Predictions were developed using Multilayer Perceptron (MLP) Back propagation Artificial Neural Network (ANN) with the advance of 1 hour. In the best ANN performance, $41.9 \%$ of the predictions obtained up to $5 \%$ of error, $58.7 \%$ obtained errors lower than $10 \%$ and $68.6 \%$ obtained errors lower than 15\%. MAPE (mean absolute percentage error) of $6.11 \%$ was found, which can be considered good, since errors found in previous works reached $20 \%$.
\end{abstract}

\section{Key words}

Solar Predictability, Solar Energy, Artificial Neural Networks.

\section{Introduction}

There is a growing search for new sources of energy worldwide in order to complement the electricity supply. Additionally, according to United Nations projections [1], in 2050 the world population will increase approximately $29 \%$, going from the current 7.55 billion inhabitants to 9.77 billion inhabitants [1]-[2], making it clear that energy demand will continue to expand. Therefore, better techniques are needed to produce, store and distribute energy, taking into account technical, financial and environmental factors.

Considering environmental impacts, different ways of introducing RE in the world energy matrix are being developed, since countries such as Brazil, China, England, Canada, Germany, among others, have signed agreements to reduce global temperature increase by limiting at $1.5^{\circ} \mathrm{C}$ above pre-industrial levels [1].

$\mathrm{RE}$ resources, such as solar, are increasingly participating in the energy matrix of several countries. Worldwide photovoltaic (PV) power has grown by approximately $50 \%$, from $228 \mathrm{GW}$ in 2015 to $303 \mathrm{GW}$ in 2016. This increase is due to policies that encourage PV panels cost reduction and technology improvement [3].

In Brazil, in 2014, the first auction to contract energy from centralized PV plants took place. In 2017, $891 \mathrm{MW}$ of PV power is expected to be operational in the Northeast, Midwest and Southeast regions of the country. The 10-year Energy Expansion Plan (PDE 2024) forecasts that the installed capacity for solar generation will reach $8.3 \mathrm{GW}$ in 2024, with $7 \mathrm{GW}$ of centralized generation and $1.3 \mathrm{GW}$ of distributed generation, representing $3.3 \%$ of the energy matrix [4].

Unlike the electricity generation from thermal sources, which can be increased or decreased according to consumption, solar generation presents intermittent characteristic. Intermittence and non-control of the generation can cause a lack or excess of electrical energy in the system [5].

Intermittence is one of the main barriers to the dissemination of PV parks in the electricity supply system. PV power is determined by local meteorological conditions and cannot be adjusted properly. As a 
consequence, additional costs arise to level unforeseen fluctuations in electricity production. Hence, energy storage and/or sources integration are necessary to supply the demand. Consumption and RE based electricity generation forecasting are also employed [6]. In Germany, those responsible for the electricity generators have to report the planned production one day in advance. The information must be fulfilled, but in case of variation, other generation units are used to balance the system. From the perspective of costs, from March to October 2010, due to errors of solar and wind forecasting in the German market, the electricity production from these sources was $2 \mathrm{GWh}$ lower than expected, resulting in an additional cost of $€ 2.20$ per $\mathrm{MWh}$ from wind and solar sources [7].

Several techniques are being used for the predictability of solar resource. Among them, ANN is widely used tool for forecasting time series. $\mathrm{ANN}$ is a processor in parallel composed of simple processing compartments, with natural propensity to store experimental knowledge and makes it accessible for use [8]. Motivated by the increasing use of PV plants in Brazil, we propose the development of techniques for the use of ANN to solar resource prediction in order to contribute to the reduction of predictability errors. Solar irradiance and ambient temperature data are collected in Fortaleza-CE (latitude: $-03^{\circ} 43^{\prime}$, longitude: $-38^{\circ} 32^{\prime}$, elevation: $21 \mathrm{~m}$ (69 ft)).

\section{Artificial Neural Network (ANN)}

ANN is a circuit composed of a large amount of simple processing units inspired by the animal neural system. ANN using MLP model is a tool used successfully in networks that have a non - linearly separable pattern. Reason for good results is the network ability to follow the standards of each class or to predict data according to a time series pattern. MLP consists of a neural network organized in layers. Input layer refers to the data, output layer and hidden layers (hidden and intermediate) are composed of neurons capable of processing data, resulting in outputs assigned through inputs excitations and respective weights. Figure 1 shows a multi-layered network having three neurons in the input layer, two neurons in the hidden layer and one in the output layer.

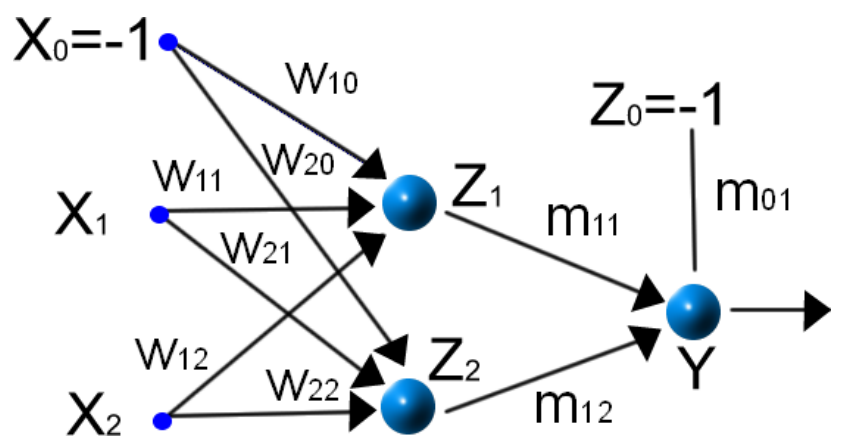

Fig. 1. MLP network model, adapted from [9].

$\mathrm{x}$ are the input data, $\mathrm{w}$ the hidden layer neurons input weights, $m$ the output layer neuron input weights and $y$ is the network output. The algorithm is a generalization of the Widrow \& Hoff delta rule for Adaline training, called backpropagation because error propagation occurs in the reverse direction of the input signal. Widrow \& Hoff Delta Rule generalization is used to adjust the weights and bias of the MLP network in order to minimize the error between the network output and the desired output. This procedure is performed for several epochs, in order to enable ANN to have adequate responses to the training data set, called network training. The weights settings, w, are also set from the output to the input.

Among the activation functions of the neurons, the activation function used for both the hidden neurons layer and the output layer was the logistic sigmoid, which generates values from 0 to 1. Equations (1) and (2) represent the function and its derivative, respectively.

$$
\begin{aligned}
& y_{i}(t)=\frac{1}{1+\exp \left[-u_{i}(t)\right]} \\
& y_{i}^{\prime}(t)=u_{i}(t)\left[1-u_{i}(t)\right]
\end{aligned}
$$

The weights updating of both the hidden and the output layer is given by equations (3) and (4).

$$
\begin{gathered}
w(t+1)=w(t)+\alpha \cdot \delta \cdot y_{i}(t) \\
b(t+1)=\mathrm{b}(t)-\alpha \cdot \delta
\end{gathered}
$$

Several lines of research for solar resource prediction have been observed with the use of ANN due to the low error rate (up to 20\%) [10], [11], [12]. Specific types of ANN are used, such as:

- Multilayer Perceptron (MLP) networks that can solve nonlinear problems and class standards;

- Radial Basic Function Networks (RBF) that can be used in curve fitting (approximation) problems and are capable of learning complex patterns and solve nonlinearly separable problems;

- Support Vector Machine (SVM), which serves for separating patterns in a hyperplane [13]-[8].

Table I shows the development of solar resource forecasts using ANN worldwide. 
Table I - ANN using MLP, RBF, SMV worldwide.

\begin{tabular}{|c|c|c|c|}
\hline AUTHOR & PARAMETER & NETWORK & COUNTRY \\
\hline $\begin{array}{c}\text { Moustris et } \\
\text { al., 2016 [13] }\end{array}$ & $\begin{array}{c}\text { Hourly solar } \\
\text { Irradiance }\end{array}$ & MLP & Greece \\
\hline $\begin{array}{c}\text { Valiki et al., } \\
2015 \text { [14] }\end{array}$ & $\begin{array}{c}\text { Hourly solar } \\
\text { Irradiance }\end{array}$ & MLP & Iran \\
\hline $\begin{array}{c}\text { Kumar and } \\
\text { Kuar, 2015 } \\
\text { [15] }\end{array}$ & $\begin{array}{c}\text { Hourly solar } \\
\text { Irradiance }\end{array}$ & MLP & India \\
\hline $\begin{array}{c}\text { Zhang et al., } \\
2014 \text { [16] }\end{array}$ & $\begin{array}{c}\text { Solar } \\
\text { Irradiance } \\
\text { every 5 } \\
\text { minutes }\end{array}$ & SVM & Canada \\
\hline $\begin{array}{c}\text { Huang et al., } \\
2015 \text { [17] }\end{array}$ & $\begin{array}{c}\text { Hourly solar } \\
\text { Irradiance }\end{array}$ & RBF & Taiwan \\
\hline $\begin{array}{c}\text { Yan et al., } \\
2014 \text { [18] }\end{array}$ & $\begin{array}{c}\text { Hourly solar } \\
\text { Irradiance }\end{array}$ & RBF & China \\
\hline $\begin{array}{c}\text { Pedro and } \\
\text { Coimbra, } \\
2012 \text { [19] }\end{array}$ & $\begin{array}{c}\text { Hourly solar } \\
\text { Irradiance } \\
\text { and }\end{array}$ & MLP & USA \\
\hline $\begin{array}{c}\text { Amirtham, } \\
2016 \text { [20] }\end{array}$ & $\begin{array}{c}\text { Irradiance } \\
\text { Solar Hour }\end{array}$ & MLP & India \\
\hline $\begin{array}{c}\text { Grimaccia et } \\
\text { al., 2017 [21] }\end{array}$ & $\begin{array}{c}\text { Irradiance } \\
\text { Solar Hour }\end{array}$ & MLP & Italy \\
\hline
\end{tabular}

\section{Methodology}

To study the solar resource intermittence, solar irradiance and temperature data collected in Fortaleza were considered in the present analysis. Irradiance Data collection was performed using a pyranometer (NRG Systems, LI-200SZ). Temperature data were obtained from a temperature sensor (NRG Systems, \# 110S), with an accuracy of $\pm 1.11^{\circ} \mathrm{C}$ and operating between $-40^{\circ} \mathrm{C}$ and $52.5^{\circ} \mathrm{C}$.

Data were collected and stored by means of spreadsheets at intervals of $10 \mathrm{~min}$, obtained by means of arithmetic means from data processed every $2 \mathrm{~s}$. Solar irradiance and temperature data were collected from May 2003 to April 2005 , totaling 24 months of data, resulting in 61,404 measurements for solar irradiance and the same for temperature, since measurements were from 05:00 hours to 18:00 hours. For MLP Backpropagation ANN training, $70 \%$ of the collected irradiance and temperature data (512 days, 43,008 measurements) were used. Figure 2 shows daily solar irradiation measurements in 2004.

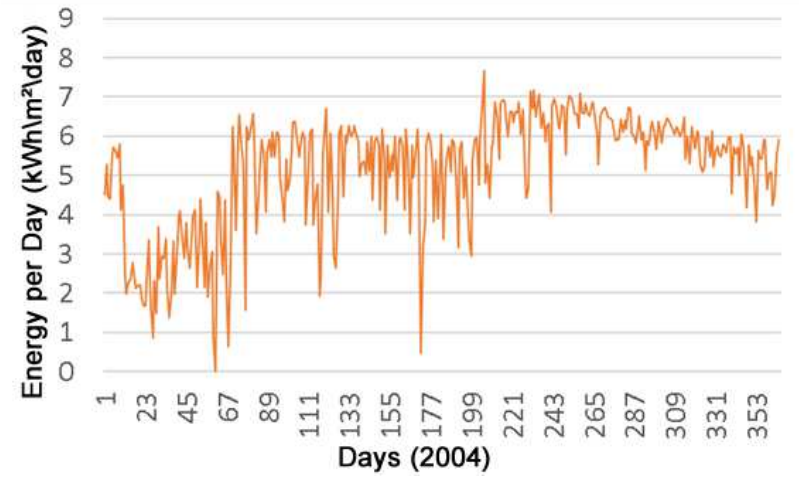

Fig. 2. Daily solar irradiation (2004).

The weather in Fortaleza is characterized by a rainy and dry season, due to the presence of the Intertropical Convergence Zone. Dry period occurs in the second half of the year. Consequently, during this period there is a higher incidence of solar irradiation on the surface due to the absence of cloud cover. Rainy season, characterized by a lower solar irradiation, occurs in the first half of the year.

For validation of the ANN results, the rest of the data (30\% of the collected data) of solar irradiance and temperature (219 days, 18,421 measurements) are used in order to verify the network operation for hitherto unknown inputs (generalization step). It is worth mentioning that, in the region of the study, the climate is well defined throughout the year, therefore, this climatic characteristic causes the neural network to be able to carry out predictions of later years.

With these results, weighted errors are calculated. Solar prediction errors are found at different times of the day, with different levels of solar resource availability [5]. If a solar prediction error happens at the end of the day, between 5 and $6 \mathrm{pm}$ in Fortaleza, the impacts of these errors on the PV electricity generation are lower than errors at 12 am, period with greater solar potential. Aiming to adjust the prediction errors taking into account the solar resource availability, a filter called Impact Factor, according to equations (5) and (6) [6], is applied.

$$
\begin{gathered}
E_{p p}=\frac{\left(D_{p}-D_{m}\right) \times 100}{D_{m}} \times F_{i} \\
F_{i}=\frac{D_{m}}{M_{r}}
\end{gathered}
$$

$E_{p p}$ is the weighted prediction error, $D_{p}$ and $D_{m}$ are the predicted and measured data, respectively, $M_{r}$ is the resource highest value and $F_{i}$ the impact factor.

Solar irradiance prediction using data collected in Fortaleza was performed using an MLP ANN with backpropagation training algorithm. The developed algorithm provides solar irradiance data one hour in advance, taking into account the events of the last 10 hours (60 measurements). The characteristics of the implemented algorithm are:

1) Matrix with 60 delays and 1 output;

2) Sigmoidal function in the vectors of the hidden and output layers;

3) 10 neurons in the hidden layer; 
4) 1 neuron in the output layer;

5) Learning rate of 0.1 ;

6) Hidden layer and output weights were initialized randomly;

7) Stop criterion was defined by the number of times, being used 10,000 times for each networking training.

Figure 3 shows the Process Flowchart.

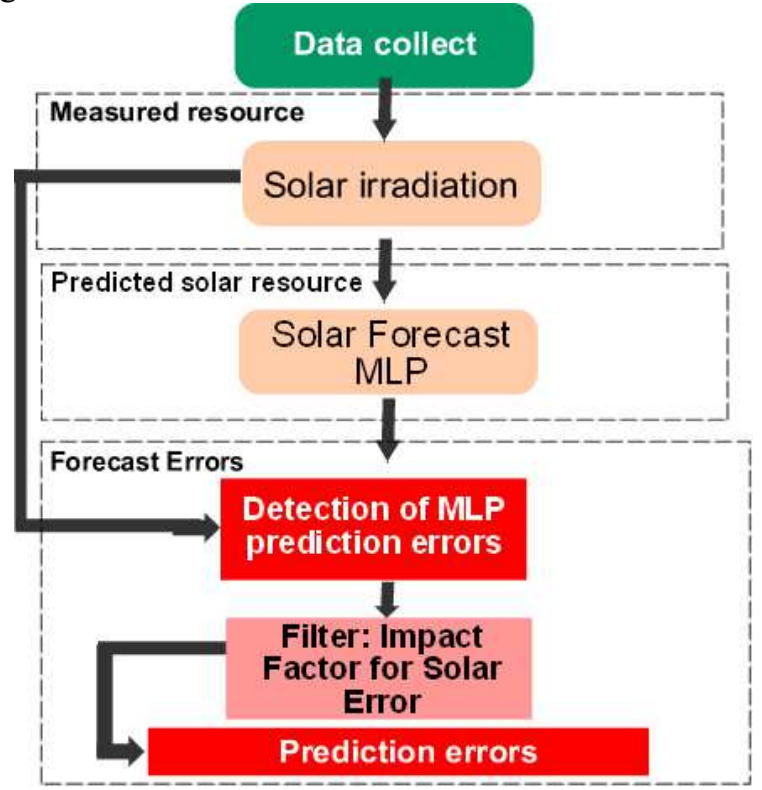

Fig. 3. Process Flowchart.

\section{Results}

Figure 4 shows solar irradiance for 5 days in April 2003. During measurements there are sudden oscillations caused by clouds. Figures 5 and 6 show comparative tests between measured and predicted solar irradiance. Prediction uses MLP Backpropagation ANN from two different training sessions, with a time delay of 10 hours (window of 60 measured data). Structure characteristics and network initialization parameters were kept, with exception of the initial weights, which were different for each of the two trainings. All measurements consider one hour in advance, totaling 18,421 forecasts, or 219 forecast days. Test period was performed from September 23, 2004 to April 30, 2005.

Predictions of solar irradiance follow the behavior of the solar resource, demonstrating that the method is able to give values close to the observations in several hours of the period. The highest value of predicted solar irradiance for the $1 \mathrm{st}$ test was $1,144.2 \mathrm{~W} / \mathrm{m}^{2}$, while the measured value was $1,371 \mathrm{~W} / \mathrm{m}^{2}$, which is an understatement of $16.6 \%$. For the second test, the highest value of predicted solar irradiance was $1,449.33 \mathrm{~W} / \mathrm{m}^{2}$, characterizing an overestimation of $5.71 \%$. For the first test, the largest difference between forecast and collected data was $99 \%$, the lowest of $0 \%$ (no error). For the second test, the largest difference was $93.77 \%$ and the lowest of $0 \%$.

In the first test, $41.9 \%$ of the predictions obtained up to $5 \%$ of error, $58.7 \%$ of the predictions obtained errors less than $10 \%$ and $68.6 \%$ of the predictions errors less than $15 \%$.

In the second test, $34.87 \%$ of the predictions obtained up to $5 \%$ of error, $53.94 \%$ of the predictions obtained errors less than $10 \%$ and $67.42 \%$ of the predictions errors less than $15 \%$. Figure 7 shows the prediction errors behavior for a 5 days window extracted from the 1 st test, chosen for representation due to its better performance.

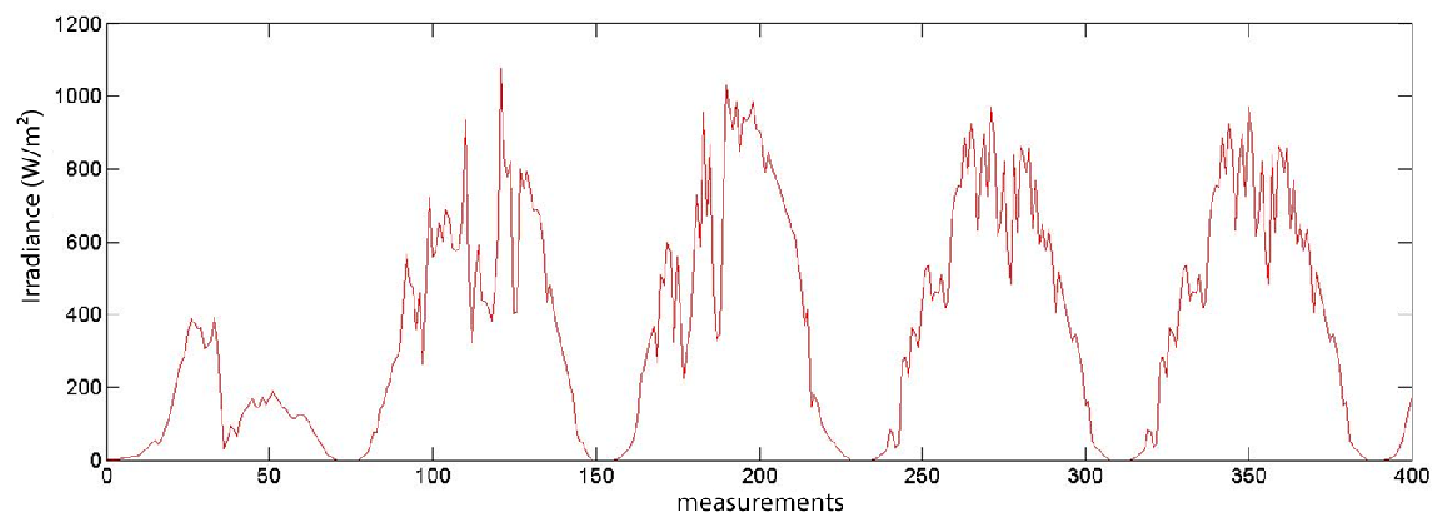

Fig. 4. Data collected in April 2003.

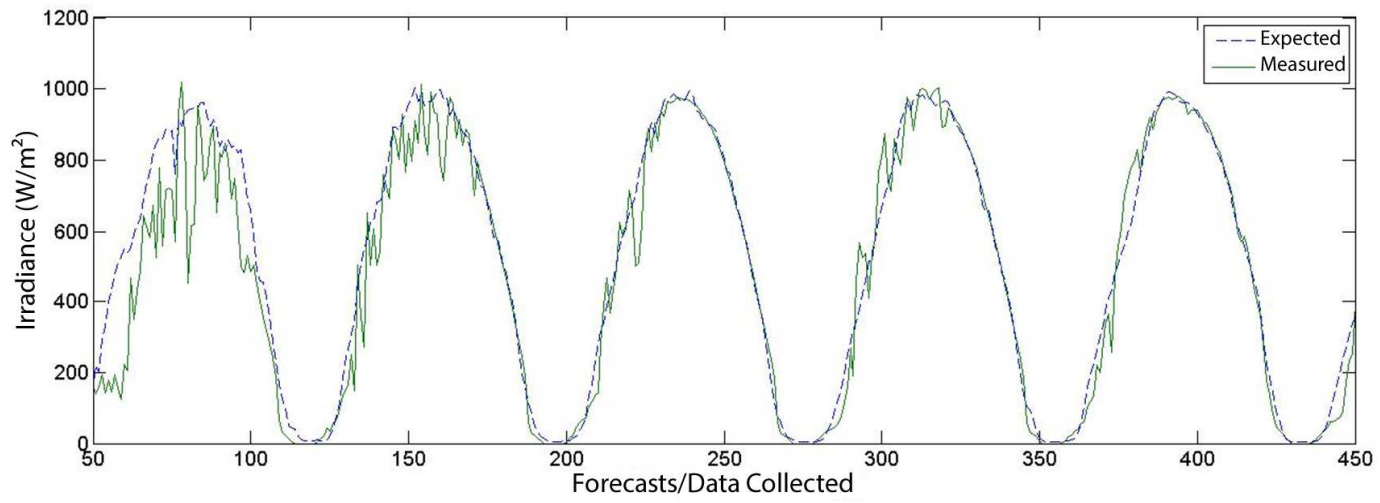

Fig. 5. Network first training test (Demonstration window: September 24 to 28, 2004). 


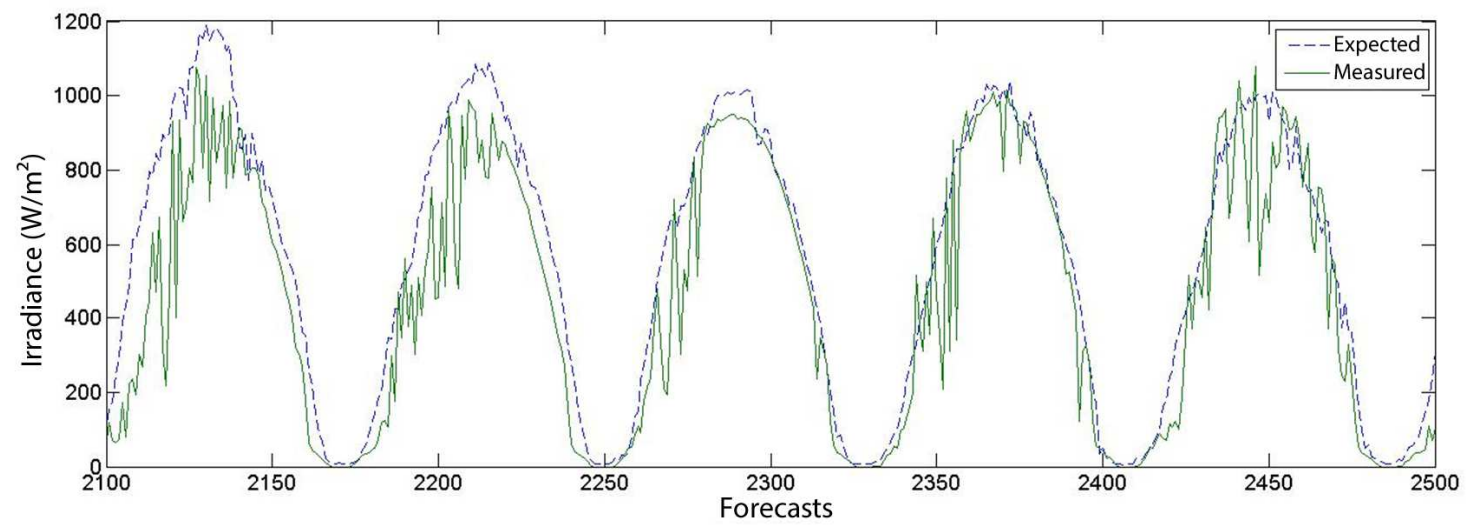

Fig. 6. Network second training test (Demonstration window: October 24 to 28, 2004).

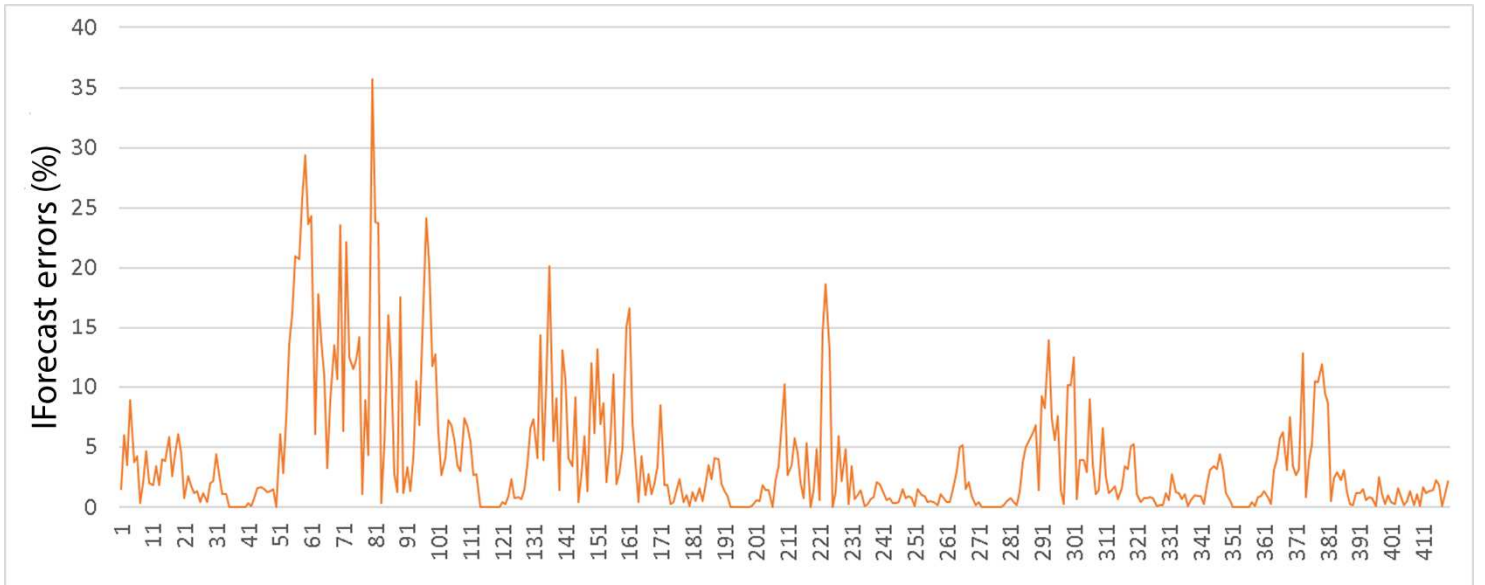

\section{Forecasts}

Fig. 7. Prediction errors.

\section{Conclusions}

The proposed MLP network was able to perform solar irradiance predictions with 1 hour in advance obtaining satisfactory results for a site close to the Equator line. In the best network performance, $41.9 \%$ of the predictions obtained up to $5 \%$ of error, $58.7 \%$ obtained errors lower than $10 \%$ and $68.6 \%$ obtained errors lower than $15 \%$. MAPE of $6.11 \%$ was found, a good value taking into account errors of previous works, which reached $20 \%$. Hence, the proposed algorithm for solar resource prediction can contribute to predictability errors decrease, causing a smoothing in the financial impacts of RE projects.

\section{References}

[1] UN - Department of Economic and Social Affairs, Population Division, "World Population Prospects: The 2017 Revision, Key Findings and Advance Tables", New York (2017), pp. 1-8.

[2] IEA, "KEY WORLD ENERGY STATISTICS", Paris (2016), pp. 26-35.

[3] REN 21, "Renewables 2017: Global Status Report." Paris (2017), pp.21-27.

[4] MME, "Plano Decenal de Expansão de Energia 2024", Brasília (2015), pp.408-411.

[5] M. A. B. F. Lima, "Teoria do Portfólio Aplicada à Previsão de Recursos Solar e Eólico". UFC, Fortaleza (2016).
[6] M. A. B. F. Lima, P. C. M. Carvalho, T. C. Carneiro, et al, "Portfolio theory applied to solar and Wind Resources Forecast", IET Renewable Power Generation, Vol. 11, Issue 7, June 2017, p. 973 - 978.

[7] V. Speth, "Wind and solar portfolios and their impact on predictability German case study 2010-2011". In Proc. 12th wind integration workshop, London, UK, October 2013, pp. 1-6.

[8] S. O. Haykin, "Neural Networks and Learning Machines", Pearson, New Jersey (2008), pp.1-930.

[9] S. Haykin, "Neural Networks: A Comprehensive Foundation, Prentice Hall, New Jersey (1999), pp.1-897.

[10] C. D. Dumitru, A. Gligor, C. Enachescu, "Solar Photovoltaic Energy Production Forecast Using Neural Networks", Procedia Technology, Elsevier, Vol. 22, February 2016, pp. 808-815.

[11] M. G. Giorgi, P. M. de Congedo, M. Malvoni, M. 2013. "Photovoltaic power forecasting using statistical methods: impact of weather data. IET Science, Measurement and Technology", Vol. 8, Issue 3, May 2014, p. 90 - 97.

[12] S. Kumar, T. Kaur, "Development of ANN Based Model for Solar Potential Assessment Using Various Meteorological Parameters", Energy Procedia, Elsevier, Vol. 90, December 2016, pp. 587-592.

[13] V. N. Vapnik, "Statistical Learning Theory", Wiley, New York (1998), pp.1-760.

[14] K. P. Moustris, K. A. Kavvadias, A. I. Kokkosis, A. G Paliatsos, "One day-ahead forecasting of mean hourly global solar irradiation for energy management systems purposes using artificial neural network modeling". In Proc. Power Generation, Transmission, Distribution and Energy Conversion (MedPower 2016), pp.1-6. 
[15] M. Vakili, S. Reza S. Yazdib, K. Kalhor. "Using Artificial Neural Networks for Prediction of Global Solar Radiation in Tehran Considering Particulate Matter Air Pollution". Energy Procedia, Elsevier, Vol. 74, August 2015, pp. 1205-1212.

[16] Y. Zhang, M. Beaudin, "Day-Ahead Power Output Forecasting for Small-Scale Solar PhotovoltaicElectricity Generators", IEEE Transactions on smart grid. Vol. 6, Issue 5, September 2015, pp. 2253 - 2262.

[17] C. M. Huang, S. J. Chen, S. P. Yang, C. J. Kuo, "One day ahead hourly forecasting for photovoltaic power generation using an intelligent method with weather-based forecasting models", IET Generation, Transmission e Distribuition, Vol. 9, Issue 14, November 2015, p. 1874 1882.

[18] C. Yan, J. Xiu, C. Liu, Z. Yang, "A High Concentrated Photovoltaic Output Power Predictive Model Based on Fuzzy Clustering and RBF Neural Network", Proceedings of CCIS2014, (2014), pp. 384-388.

[19] H. T. C. Pedro, C. F. M. Coimbra "Assessment of forecasting techniques for solar power production with no exogenous inputs". Solar Energy, Elsevier, Vol. 86, Issue 7, July 2012, pp. 2017-2028.

[20] P. Neelamegam, V. A. Amirtham, "Prediction of solar radiation for solar systems by using ANN models with different backpropagation algorithms", Journal of Applied Research and Technology, Elsevier, Vol. 14, Issue 3, June 2016, pp. 206-214.

[21] F. Grimaccia, S. Leva, M. Mussetta, E. Ogliari, "ANN Sizing Procedure for the Day-Ahead Output Power Forecast of a PV Plant" Applied Sciences, MDPI, Vol. 7, Issue 6, June 2017, pp. 622-635. 